\title{
Femtosecond laser-assisted anterior lamellar keratoplasty (FSALK) versus microkeratome- assisted anterior lamellar keratoplasty (MALK) for the treatment of anterior corneal dystrophy.
}

\author{
Radwan Almousa ${ }^{1,2}$, Sheraz M. Daya ${ }^{1,3}$ \\ ${ }^{1}$ Corneoplastic Unit, Queen Victoria Hospital, East Grinstead, United Kingdom; \\ Ophthalmology Department, University Hospitals Coventry and Warwickshire, \\ United Kingdom; ${ }^{3}$ Private clinic, Center for Sight, East Grinstead, United Kingdom.
}

\begin{abstract}
Purpose: To compare the visual outcome of femtosecond laser-assisted anterior keratoplasty (FSALK) and microkeratome-assisted anterior lamellar keratoplasty (MALK) in anterior corneal dystrophy.

Methods: retrospective comparative chart review of 7 eyes that underwent FSALK and 7 eyes that underwent MALK. The primary outcome was the visual outcome of both procedures. The secondary outcome was the recurrence of the corneal dystrophies.


$127 \pm 28(80-127)$ months for the MALK group. In the FSALK group the preoperative best spectacle-corrected visual acuity (BSCVA) improved from 20/63 to 20/25 at 36 months. In the MALK group there was 1 eye with documented BSCVA over 36 months follow-up; it improved from 20/160 preoperatively to 20/32 at 36 months. Uncorrected visual acuity (UCVA) at 36 months improved from 20/100 preoperatively to 20/63 in the FSALK group and from 20/200 preoperatively to 20/63 in the MALK group. Five eyes with Reis-Bucklers showed a clinical recurrence at a mean of 142 $\pm 13(125-152)$ months. Two eyes with granular dystrophy showed a clinical recurrence at 23 and 80 months of follow-up. One eye in the MALK group had epithelial ingrowth. One eye in the FSALK group with compromised ocular surface due to 2 previous penetrating keratoplasty, suffered bacterial keratitis that ended up with corneal scarring.

Conclusion: Both procedures improve visual outcome for anterior corneal dystrophy. FSALK has theoretical advantages over MALK; however, larger prospective studies are needed to prove this.
\end{abstract}

Keywords: Corneal dystrophy; femtosecond; microkeratome; anterior keratoplasty.

\section{Introduction}

Corneal dystrophies are defined as primary, inherited, bilateral disorders of the cornea affecting transparency, leading to varying degrees of visual disturbances. ${ }^{1}$ Clinically, corneal dystrophies are said to be of early onset, axially symmetric, slowly progressive or stationary, free from vascularization, and not associated with other systemic conditions. Known exceptions are the unilateral presentation in Meesman

Correspondence: Radwan Almousa, Ophthalmology Department, University Hospitals Coventry and Warwickshire NHS Trust, Coventry CV2 2DX, UK.

E-mail: radomousa@rodomousa.com 
and lattice dystrophy, vascularization in gelatinous drop-like keratopathy, and delayed presentations in the case of Fuchs Dystrophy. ${ }^{1,2}$

Corneal dystrophies with primarily anterior involvement such as Bowman's layer, granular, and lattice dystrophies share similar clinical presentation with visual disturbances. The recurrent erosions are mainly associated with Bowman's layer dystrophy in the early years of life and to a less extent with the granular and lattice dystrophies. ${ }^{3}$

When diminished vision is such that intervention is required, lamellar keratoplasty (LK) and penetrating keratoplasty (PK) have been the procedures of choice. ${ }^{4,5}$ LK has many advantages over PK. Avoiding full thickness trephination minimizes potential intraoperative complications and allows faster visual recovery. Maintaining the host endothelium prevents endothelium rejection. Furthermore, LK allows multiple lamellar (anterior, stromal, endothelial) corneal transplantations to be performed from one donor cornea. ${ }^{6}$

The major limitation of $\mathrm{LK}$ is the technical challenge of performing manual dissections: the resulting stromal irregularities between the donor and the recipient interface could affect visual outcome. Improvements in automated microkeratomes and artificial anterior chambers minimize these difficulties. ${ }^{7}$ Use of the femtosecond (FS) laser optimizes the LK technique by augmenting the precision of lamellar dissections and side cuts. The smooth interface should in theory improve visual results.,9 Femtosecond-assisted lamellar keratoplasty (FSALK) also has less chance of causing a microperforation, and allows visualization of the cornea during lamellar dissection that allows the procedure to be stopped if technical incidents occur.

We designed this retrospective study to compare the visual outcome of microkeratome-assisted anterior lamellar keratoplasty (MALK) and FSALK in the treatment of anterior corneal dystrophy. Secondary outcomes were corneal dystrophy recurrence, graft survival and complications associated with these procedures.

\section{Materials and Methods}

This was a retrospective study of the patients with anterior corneal dystrophy that were followed up between July 1997 and July 2010. The study was conducted at a corneal tertiary referral center in the south west of England and it was approved by the institutional review board and followed the tenets of the Helsinki declaration.

We retrieved the notes of 133 patients with the term "corneal hereditary dystrophy" using the hospital based audit department coding system. Only the notes of patients with the diagnosis of RB, granular, and lattice dystrophies were reviewed.

\section{Inclusion and Exclusion criteria}

Inclusion criteria were corneal dystrophies involving Bowman's layer (Reis-Bucklers) or the anterior cornea (lattice and granular), and eyes that had either MALK or FSALK as a surgical treatment for the corneal dystrophy. Exclusion criteria were follow-up of less than 6 months, eyes that did not have FSALK or MALK as part of the corneal dystrophy management, extensive missing data, and patients with any 
other condition that could significantly affect their visual acuity (e.g. advanced age related macula degeneration, severe glaucoma).

\section{Surgical technique}

All procedures were performed under topical anesthesia. Anterior segment ocular coherence tomography (OCT: Visante OCT, model 1000, Carl Zeiss Meditec, Dublin, CA, USA) was used in all patients to assess the depth of the corneal pathology that needed to be removed. To prepare the donor corneal graft, corneoscleral donor tissue was mounted on an artificial anterior chamber maintainer. In the MALK

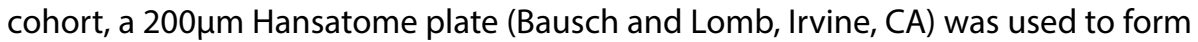
the donor and the recipient corneal graft. Graft diameter was the same in both donor and host, ranging from from 8 to $9 \mathrm{~mm}$. Only in one patient with high myopia (-9D) secondary to a previous penetrating keratoplasty (PK), the donor lenitcule was made smaller by $1 \mathrm{~mm}$ (donor: $8 \mathrm{~mm}$, host: $9 \mathrm{~mm}$ ) to overcome the step cornea. In the FSALK cohort, the donor graft was created using an Intralase FS laser (AMO, Santa Ana, CA, USA). The software of the laser was regularly updated throughout the duration of the study (frequency range: 15 to 60 kilohertz). The following settings were used for the donor graft: donor lenticule thickness, 145 to $230 \mu \mathrm{m}$. Lenticule thickness was adjusted in relation to the depth of the lesions as shown on the OCT findings.

Donor lenticule diameter ranged from 7.8 to $8.7 \mathrm{~mm}$. Lamellar cut energy was 0.95 to 1.2 microjoules; side cut energy was 1 to 1.3 microjoules; side cut angle $70^{\circ}$ in 6 eyes and $120^{\circ}$ in one eye; lamellar spot and line separation 6 to 12.

Only 1 donor lenticule had the same thickness as the recipient corneal lenticule. Additional thickness was added to the donor lenticule to compensate for edema in 6 grafts, ranging from 20 to $30 \mu \mathrm{m}$.

A recipient corneal lenticule was created using similar FS laser settings, however; the host lenticule was set to be smaller in diameter than the donor lenticule (range 0 to $0.2 \mathrm{~mm}$ ). The host lenticule was then removed and replaced by the donor lenticule. Five patients in the FSALK cohort and 1 patient in the MALK cohort had additional phototherapeutic keratectomy (PTK) surgery on the stromal bed of the host cornea before applying the donor lenticule to improve the visual outcome or to remove residual corneal pathology. Laser ablation was performed using the Technolas 217C (Bausch \& Lomb, Rochester, NY). The ablation was performed with 6 to $7 \mathrm{~mm}$ diameter without a transition zone and with a depth of an average of 70 $\mu \mathrm{m}$ (range: 50 to 100 ).

All grafts in the FSALK cohort were sutured in place with 10/0 nylon; 6 grafts had interrupted sutures, and $1 \mathrm{graft}$ had overlay sutures. In the MALK cohort 3 grafts were placed without suturing, 3 with interrupted sutures, and one graft with overlay sutures. Patients were placed on topical antibiotic and steroid drops for 1 month; the topical steroids were tapered over a few months.

The removal of sutures was carried out at $6 \pm 5$ (1-15) weeks for the FSALK group and at $5 \pm 0.5$ (4-5) weeks for the MALK group. 


\section{Data collection}

Baseline demographic information was collected for each eye of the patient recruited in the study. Numerical results were presented as mean \pm standard deviation, range. Surgical procedures that were performed before the study period were determined. The first anterior lamellar keratoplasty (ALK) during the study period was referred to as the index surgery. The following refractive data were collected before the index surgery and at $1,3,6,12,24 \pm 3,36 \pm 3$ months postoperatively: uncorrected visual acuity (UCVA), best spectacle-corrected visual acuity (BSCVA), manifest refraction spherical equivalent (MRSE), mean $\mathrm{K}$ readings. These refractive outcomes were also documented 3 months after any further refractive surgery. Graft failure was diagnosed as a stromal opacification due to recurrence of the original disease or as a result of microbial keratitis, causing a loss of 2 lines or more of BSCVA.

Simple recurrence of the dystrophy was documented as the heterogeneous haze of the cornea, with distinct patterns resembling the original dystrophy with or without subjective symptoms. Stromal haze related to the excimer laser was usually homogeneous over the entire ablation zone in most eyes and was also less dense than a recurrence. The complications related to the index surgery were noted. Stromal rejection was diagnosed if there were sub-Bowman infiltrates on the donor tissues, which resemble that of adenoviral infection without conjunctival injection and with positive response to topical corticosteroid therapy (Figure 1).



Fig. 1. One eye in the Femtosecond laserassisted anterior lamellar keratoplasty cohort showing signs of corneal graft stromal rejection with sub-Bowman's infiltrate in the donor tissue, which resemble that of adenoviral epidemic keratoconjunctivitis.

\section{Statistical analysis}

We used XLSTAT 2010 Mac software (Addinsoft, NY, USA) for statistical analysis. Visual acuity data converted to the logarithm of the minimum angle of resolution (logMAR). The following conversion to logMAR was used for vision worse than 20/400: counting fingers $=1.6$, hand movements $=2.0 .^{10}$ The distribution of data was examined using the Shapiro-Wilk test of normality. Friedman test was applied to the comparisons of refractive outcome between different moments for each 
group. For quantitative variables, the student t-test or the Mann-Whitney $U$ tests were used, as appropriate, to compare the outcome between groups. Student t-test was used for paired comparison. To evaluate differences in proportions, the Chi-square test or Fisher exact test was employed as needed. Kaplan-Meyer survival analysis was performed to estimate the probability of corneal dystrophies recurrence. Log-rank test was used to compare the recurrence rate between the different corneal dystrophy. $P$ values less than 0.05 were considered significant.

The safety index is determined as the mean postoperative BSCVA/mean preoperative BSCVA (in Decimal fraction). Efficacy index is determined as the mean postoperative UCVA/mean preoperative BSCVA (in Decimal fraction).

\section{Results}

We reviewed the notes of 25 eyes with anterior corneal dystrophy. We excluded the eyes that had no surgical intervention as part of their management ( 3 eyes), or that had surgical intervention not in the inclusion criteria (penetrating keratoplasty, deep anterior lamellar keratoplasty, phototherapeutic keratoplasty) (6 eyes), or with extensive missing data (2 eyes). Fourteen eyes (7 FSALK, 7 MALK) from 9 patients were included for further analysis: some patients had a FSALK for one eye and MALK for the other eye, hence the comparison between both groups was carried out per eye rather than per patient. The baseline factors including age, BSCVA, UCVA, topographic keratometry, and MRSE did not differ significantly between groups. Despite the similarity between the 2 groups, the MALK group had significantly longer follow up (Table 1). Most of the corneal dystrophies were RB in both groups (5/7 in the FSALK and 6/7 in the MALK group) and the rest were granular dystrophy with no case of lattice dystrophy included.

Three eyes in the FSALK group had previous PK and the rest (4/7 eyes) were naïve. In the MALK group 5/7 eyes were naïve and one eye had previous PK then DALK, one eye had 1 PK, and one eye had PK then laser-assisted in situ keratomileusis (LASIK) then trabeculectomy. 
Table 1: Patients characteristics and baseline data for microkeratome-assisted anterior lamellar keratoplasty (MALK) and femtosecond-assisted anterior lamellar keratoplasty (FSALK) groups.

\begin{tabular}{|c|c|c|c|}
\hline $\begin{array}{l}\text { Patients charactereistics } \\
\text { and baseline date }\end{array}$ & $\begin{array}{l}\text { FSALK } \\
\text { No }\end{array}$ & $\begin{array}{l}\text { MALK } \\
\text { No }\end{array}$ & $P$ value* \\
\hline Number of eyes & 7 & 7 & \\
\hline $\begin{array}{l}\text { Laterality } \\
\text { Right } \\
\text { Left }\end{array}$ & $\begin{array}{l}4 \\
3\end{array}$ & $\begin{array}{l}4 \\
3\end{array}$ & 1.0 \\
\hline $\begin{array}{l}\text { Corneal disease } \\
\text { Reis-Bucklers dystrophy } \\
\text { Granular dystrophy } \\
\text { Lattice dystrophy }\end{array}$ & $\begin{array}{l}5 \\
2 \\
0\end{array}$ & $\begin{array}{l}6 \\
1 \\
0\end{array}$ & 0.51 \\
\hline Age at the index surgery $t$ & $37 \pm 7(25-45)$ & $41 \pm 13(25-62)$ & 0.59 \\
\hline Age at the first surgery $\dagger$ & $32 \pm 11(17-45)$ & $35 \pm 12(25-52)$ & 0.59 \\
\hline $\begin{array}{l}\text { Age at the start of } \\
\text { the recurrent erosion } \\
\text { syndromet }\end{array}$ & $11 \pm 11(3-25)$ & $4 \pm 2(3-7)$ & 0.24 \\
\hline $\begin{array}{l}\text { Age at the start of visual } \\
\text { deterioration } \dagger\end{array}$ & $21 \pm 3(16-26)$ & $20 \pm 5(16-29)$ & 0.81 \\
\hline BSCVA before surgery† & $0.3 \pm 0.1(0.1-0.6)$ & $0.4 \pm 0.3(0.2-0.9)$ & 0.4 \\
\hline UCVA before surgery† & $0.7 \pm 0.2(0.5-1.0)$ & $0.8 \pm 0.4(0.4-1.3)$ & 0.3 \\
\hline Topographic K reading ${ }^{-}$ & $45 \pm 4.2(40.5-52.25)$ & $43.0 \pm 2.5(40.5-49)$ & 0.43 \\
\hline MRSE† & $-3 \pm 3.3(-10$ to 0.3$)$ & $-1 \pm(-7$ to 1.5$)$ & 0.35 \\
\hline Follow-up in months & $30 \pm 14(7-51)$ & $127 \pm 28(80-127)$ & $<0.0001$ \\
\hline $\begin{array}{l}\text { Family history } \\
\text { Yes } \\
\text { No } \\
\text { Unknown }\end{array}$ & $\begin{array}{l}5 \\
1 \\
1\end{array}$ & $\begin{array}{l}6 \\
1 \\
0\end{array}$ & \\
\hline $\begin{array}{l}\text { Indication for index } \\
\text { surgery } \\
\text { Visual } \\
\text { Recurrent erosion } \\
\text { syndrome }\end{array}$ & $\begin{array}{l}7 \\
0\end{array}$ & $\begin{array}{l}7 \\
0\end{array}$ & \\
\hline \multicolumn{4}{|c|}{$\begin{array}{l}\text { BSCVA: best spectacle corrected visual acuity, UCVA: uncorrected visual acuity, MRSE: } \\
\text { manifest refraction spherical equivalent. } \\
\text { *P values were obtained by Chi-square or Fisher's exact test as needed for qualitative } \\
\text { variables, and by student t-test or Mann-Whitney U test for quantitative variables. } \\
\text { † mean } \pm \text { standard deviation (range) }\end{array}$} \\
\hline
\end{tabular}


None of the eyes in the FSALK group had further surgery. In the MALK group one naiive eye had lifting of the graft with washing of the stromal bed to clean epithelial ingrowth, 4 days after the index surgery, then the graft had to be replaced 14 months later due to the epithelial ingrowth. The eye underwent LASIK surgery followed by photorefractive keratectomy (PTK), 38 and 155 months respectively, after the index surgery to correct residual refractive error. One eye had PK one year following the index surgery to correct high astigmatism related to a previous PK that was performed before the index surgery, and another eye had two PTK procedures following the index surgery to correct high astigmatism related to a previous PK.

\section{BSCVA progression over 36 months:}

The patients in the FSALK group started to show improvement in the mean BSCVA at 6 months and achieved their best BSCVA at 24 months (Figure 2), however; this improvement did not reach significant difference at any point comparing to preoperative BSCVA.

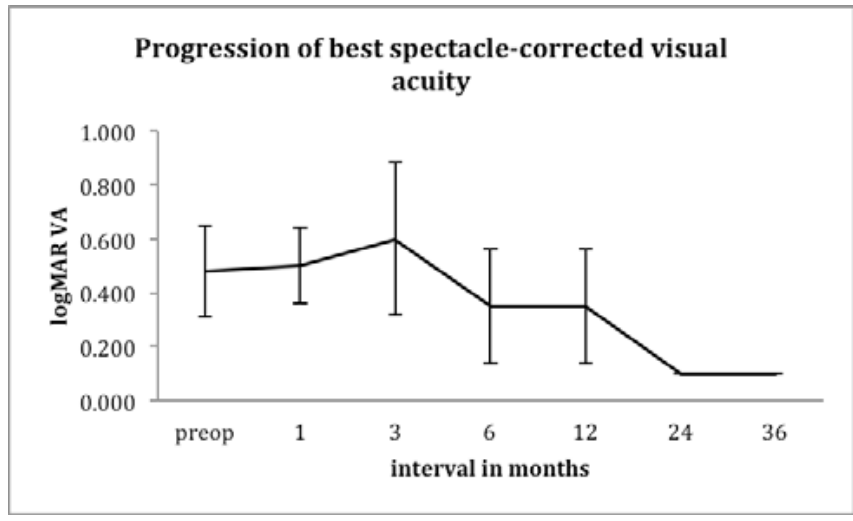

Fig. 2. Progression of best spectacle-corrected visual acuity postoperatively in the FSALK group. The improvement was evident at 6 months postoperatively with maximum improvement at 24 months postoperatively $(P=0.138$, Friedman's test).

In the FSALK group 4/7 eyes had BSCVA $<20 / 40$ (mean 20/63, range 20/32 to 20/80) preoperatively and the BSCVA improved to a mean of 20/40 at 6 and 12 months, and 20/25 at 24 and 36 months of follow-up. At 12 months of follow-up $3 / 5$ eyes gained an average of $2.5 \pm 1$ (2-4) lines of BSCVA, 1 eye neither gained nor lost preoperative lines, one eye lost 2 lines of preoperative BSCVA. At 24 months of follow-up, $3 / 3$ eyes gained an average of 2.5 \pm 2.2 (0.5-5) lines of BSCVA. At 36 months of follow-up, 3/4 eyes gained an average of 3 31.7 (2-5) lines, 1 eye lost 4 lines of preoperative BSCVA due to graft failure as a result of bacterial keratitis secondary to chronic epithelial defect.

In the MALK group, 2/7 eyes had BSCVA $<20 / 40$ preoperatively, 1 eye had BSCVA of 20/32 and another eye with BSCVA of 20/40, and 3 eyes had no preoperative BSCVA documentation. Over 36 months of follow-up, 1 eye only had documentation of BSCVA and it showed improvement of 6,7 , and 7 lines at 12, 24, and 36 months respectively. BSCVA improved from $20 / 160$ preoperatively to 20/63 at 6 months, 20/40 at 12 months, and 20/32 at 24 and 36 months of follow-up. 


\section{UCVA progression over 36 months:}

Both groups showed improvement of UCVA over the 36 months follow-up, without significant difference between the two groups.

In the FSALK group, the mean UCVA started to improve at 6 months postoperatively with maximum improvement at 24 months postoperatively $(P=0.053)$ (Figure 3 ).

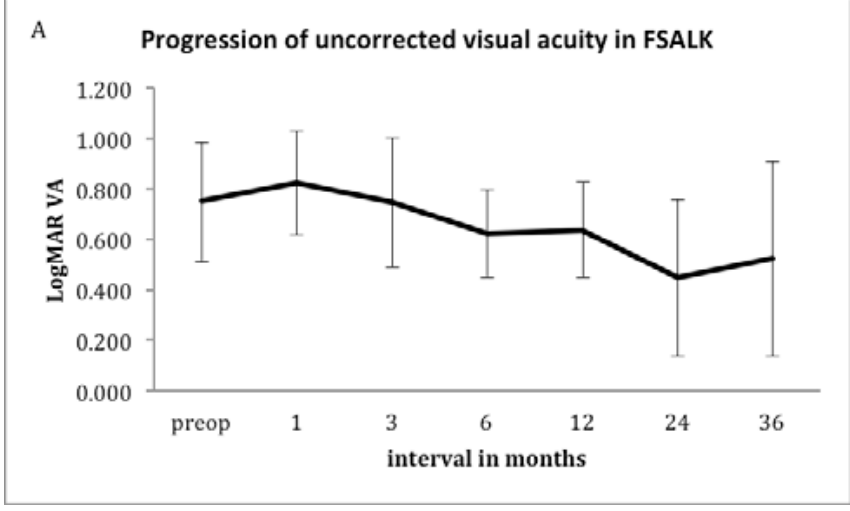

B

Progression of uncorrected visual acuity in MALK

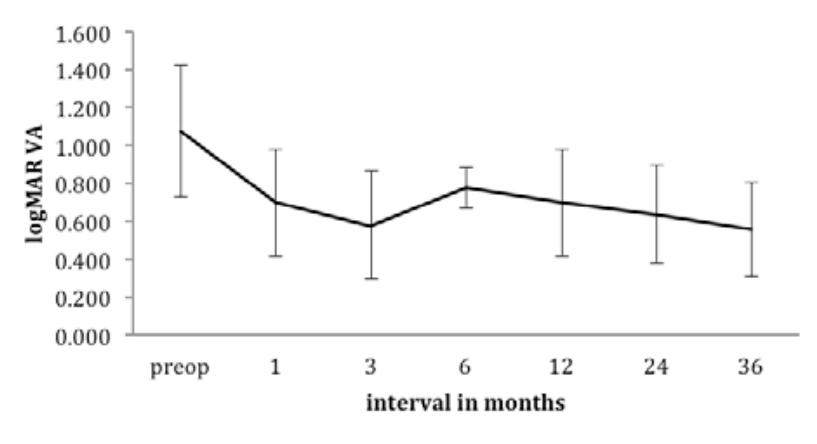

Fig. 3. Progression of uncorrected visual acuity postoperatively in the FSALK and MALK.

A. In the FSALK the improvement was evident at 6 months with maximum improvement at 24 months postoperatively $(P=0.053$ Student t test).

B. In the MALK group the improvement was evident at 1 month with maximum improvement at 3 and 36 months postoperatively ( $P=0.004$, Friedman's test).

All the eyes in the FSALK group had preoperative UCVA of $<20 / 40$ (mean 20/100, range 20/63 to 20/200). The UCVA improved to a mean of 20/80 at 6 and 12 months, $20 / 50$ at 24 months, and 20/63 at 36 months of follow-up. At 12 months of followup, 3/6 eyes gained an average of 4.5 \pm 1.5 (3-6) lines of UCVA, 2 eyes lost 2 lines of preoperative UCVA and 1 eye neither gained nor lost preoperative lines. At 24 months of follow-up, 5/6 eyes gained an average of 3.2 1.9 (2-6) lines of UCVA and 1 eye lost 1 line of preoperative UCVA. At 36 months of follow-up, 4/4 eyes gained an average of $2 \pm 1.4$ (1-4) lines.

In the MALK group, the UCVA showed significant improvement at 24 and 36 months postoperatively ( $P=0.03$ and $P=0.02$ respectively). The improvement in UCVA was evident at the first month postoperatively and it reached the maximum at 3 and then at 36 months postoperatively (Figure 3 ). 
In the MALK group, all the eyes had preoperative UCVA $<20 / 40$ (mean 20/200, range 20/63 to counting fingers). Postoperatively, the UCVA improved to a mean of 20/125 at 6 months, 20/100 at 12 months, 20/80 at 24 months, and 20/63 at 36 months of follow-up. At 12 months of follow-up, 5/7 eyes gained an average of 3.8 1.7 (1-5) lines of UCVA, 1 eye lost 3 lines due to epithelium ingrowth and another eye lost 1 lines of preoperative UCVA due to high astigmatism related to previous PK that was done before the index surgery. At 24 months of follow-up, 5/5 eyes gained an average of $4.4 \pm 2.3$ (1-6) lines. At 36 months of follow-up, $5 / 5$ eyes gained an average of $5 \pm 3(1-7)$ lines.

The safety index for FSALK group was 1.25, 1.57, and 1.25 at 12, 24, and 36 month postoperatively. The efficacy index for FSALK was $0.62,0.8$, and 0.8 at 12,24 , and 36 months postoperatively.

We could not assess the safety/efficacy index for the MALK group, as there was only 1 eye with postoperative documented BSCVA.

\section{Manifest refraction spherical equivalent (MRSE)}

FSALK group showed emmetropic shift towards slight myopia over 36 months postoperatively (Figure 5), although, the shift was not statistically significant ( $P=0.42$ for FSALK, Friedman's test).

We did not assess the MRSE value for MALK group, as there was only one eye in the MALK group that had BSCVA documentation over 36 months.

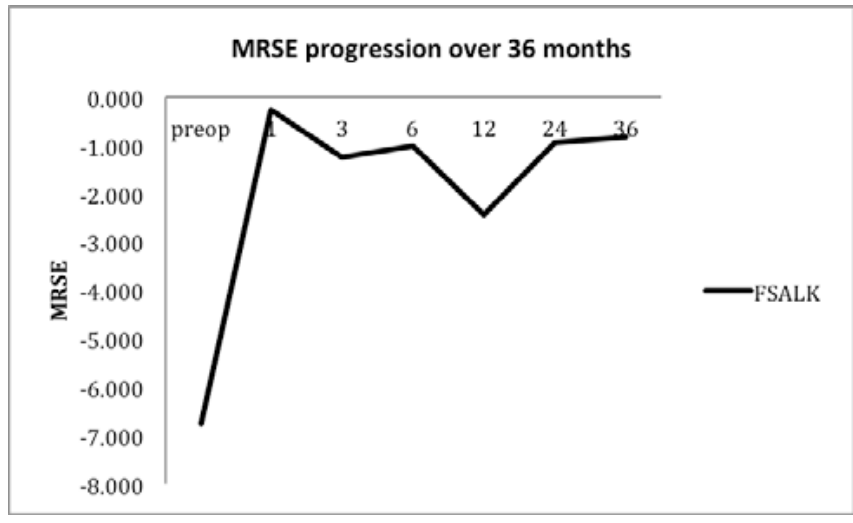

Fig 5. Progression of manifest refraction spherical epuivalent for FSALK group with emmtropic effect towards slight myopia.

\section{Keratometric reading}

In the FSALK group there was a reduction of the mean keratometric $(K)$ reading postoperatively, and this reduction was mainly in the eyes $(n=5)$ that had associated PTK treatment (Figure 6), as for the other 2 eyes that had mainly FSALK, there was no change in the mean $\mathrm{K}$ reading ( $\mathrm{K}=49.5$ preoperatively vs $\mathrm{K}=49.5$ at 36 months postoperatively).

In the MALK group, $\mathrm{K}$ reading showed no statistical difference comparing to preoperative measures at any point. 
Evidence of recurrence was noted in 1 eye in the FSALK group and 6 eyes in the MALK group; however, the MALK group had a significantly longer follow-up period (127 vs. 30 months). We have added both groups for dystrophy recurrence assessment, as the surgical procedure in both groups should not affect the recurrence interval. Over a mean follow-up of $79 \pm 54$ months, Kaplan-Meier survival analysis shows a mean time to recurrence of $72 \pm 11$ (95\% Cl 50.1-94.6) months (Figure 7). One eye in the FSALK group with granular dystrophy had a recurrence at 23 months. In the MALK group 6/7 eyes had recurrences of the dystrophy: 5 of them were RB dystrophy with a mean recurrence interval at 142 $\pm 13(125-152)$ months. The one eye that was treated with MALK procedure for granular dystrophy had a recurrence at 80 months. Granular dystrophy had a significantly shorter time to recurrence compared with $\mathrm{RB}$ dystrophy ( $P=0.016$. Log-rank test).

One graft in the FSALK failed at 32 months postoperatively due to bacterial keratitis resulting from persistant epithelial defect. One graft in the MALK group failed due to epithelial ingrowth.

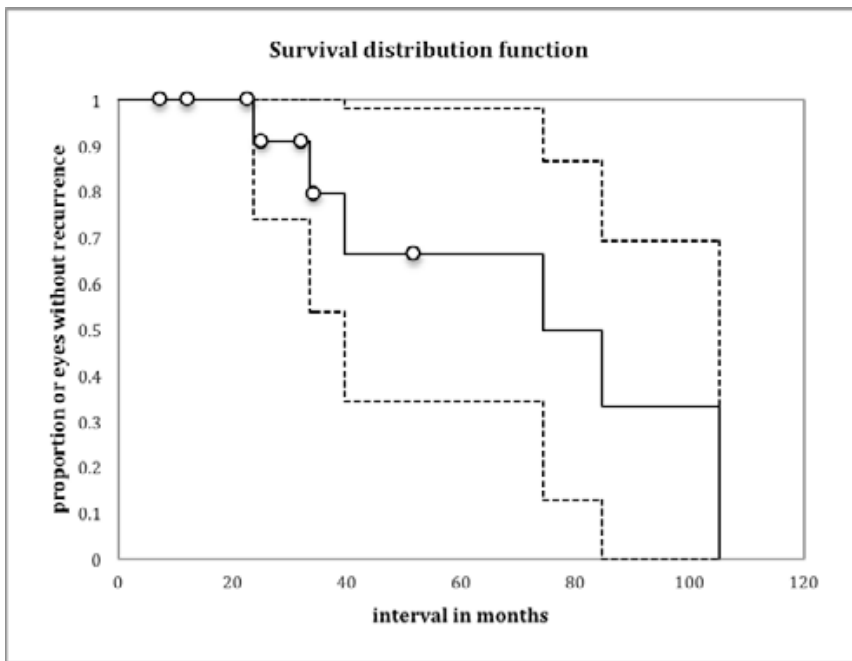

Fig. 7. Kaplan-Meier survival analysis for the recurrence of the corneal dystrophy postoperatively. Mean recurrence time was 72 \pm 11 (95\% Cl 50.1-94.6). The percentages of clear corneal after 2, 3, and 4 years following the index surgery, were $90 \%, 79 \%$, and $66 \%$ respectively. Solid line is the mean data and the doted lines are the upper and lower bound of the $95 \%$ confidence interval.

\section{Complications:}

One naïve eye that underwent a MALK had epithelium ingrowth under the corneal graft, which was treated with lifting of the graft and washing the stromal bed 7 days postoperatively. As the epithelium cells were still evident under the graft, it was replaced 14 months later with another anterior lamellar graft, resulting in UCVA of 20/50. This eye had further LASIK surgery 24 months later with resulting UCVA of 20/20. One MALK eye experienced stromal rejection 7 months postoperatively and it was controlled with topical steroid treatment. One MALK eye experienced slipped lenticule 1 week postoperatively, as the graft was fashioned to be $1 \mathrm{~mm}$ smaller than the host bed to overcome high myopia (-7D) that resulted from a previous PK surgery. The lenticule was sutured back to the host and the sutures were removed after 1 month. 
One eye that had 2 PK for RB dystrophy, followed by FSALK, suffered bacterial keratitis 32 months after the FSALK resulting in corneal scar and graft failure.

\section{Discussion}

Anterior lamellar keratoplasty is considered to be convenient for anterior corneal dystrophy and less invasive than the full thickness graft used as the conventional treatment. The fact that the dystrophy recurs after corneal grafting multiplies the risks of the full thickness graft. ${ }^{11,12}$

Invasive procedures can cause an acceleration of the dystrophy. However, once a cornea has been grafted, the dystrophy often appears to be more anteriorly situated $^{13}$; hence, the ALK is a suitable procedure for both naïve eyes and eyes that have undergone previous surgery.

Anterior lamellar keratoplasty was performed in the early days with microkeratome (MALK). When the femtosecond technology became available, we started to use FSALK, and it is now the main treatment for anterior corneal dystrophy in our practice. We found no significant difference in visual outcome between the MALK and FSALK groups; however, there is growing evidence of the high precision and reproducibility of femtosecond laser-assisted lamellar corneal incisions. ${ }^{14}$ This focusable infrared laser is capable of cutting corneal tissue of various depths with minimal corneal collateral tissue damage measured to be in the order of $1 \mu \mathrm{m}$. These capabilities are also less hampered by optical haze, compared with other lasers using visible wavelengths, and thus more capable of cutting opacified corneas. ${ }^{15}$

Evidence of dystrophy recurrence was noted in $50 \%$ of cornea over a mean follow-up of $79 \pm 54$ months, with an average recurrence at 72 months. The granular dystrophy recurrence was noted to recur relatively early, with 2 cases recurring at 23 and 80 months. RB dystrophy, on the other hand, showed signs of recurrence late, at 142 \pm 13 (125-152) months. Dinh et al. noted the recurrence of RB dystrophy in 10 of 17 PTK procedures after a mean of 12.3 (range 5.6-19.8) months; in 7 of 13 PTKs performed for granular dystrophy after a mean of 31.9 (range 22.5-48.4) months; and in 1 of 7 eyes with lattice dystrophy, 5.4 months post PTK. ${ }^{16}$ They suggested that the granular dystrophy was the slowest to recur. However, in our series, granular dystrophy recurred significantly earlier than RB. In the case series of Lyons et al., consisting of $20 \mathrm{PK}$ and 11 lamellar keratoplasties for granular dystrophy, the granular dystrophy recurrence was observed in almost all grafts within a range of 13 to 36 months after surgery, and the recurrence-free interval was not longer after PK than lamellar grafts. ${ }^{17}$

The FSALK group showed a trend of BSCVA improvement over 36 months of follow-up; however, it was not statistically significant. The BSCVA improved from $20 / 63$ preoperatively to $20 / 40$ at 6 months and reached maximum at 24 months postoperatively with BSCVA of 20/25. Abou Shousha $M$ et al. describe a series of FSALK patients, who achieved their best BSCVA at 8 months. ${ }^{18}$ This series consisted of naïve eyes (no previous corneal surgery) with mainly anterior corneal scar as an indication for surgery, and the surgery was sutureless. In comparison, our FSALK cohort comprised 3 eyes that had previous PK surgery and 4 naïve eyes. Furthermore, 
all the eyes in our FSALK series had sutures that were removed at an average of 6 weeks postoperatively, which would explain the slower visual rehabilitation.

In the MALK group we employed a microkeratome head with $200 \mu \mathrm{m}$ slit to cut the recipient and donor head. Published data have shown that all microkeratome heads cut somewhat more thickly than expected ${ }^{19}$, mainly because corneal tissue is squeezed through the slit while being dissected, and that could explain the less need for the associated PTK to remove residual host stromal opacity (5 eye is FSALK vs 1 eye in MALK) and the earlier improvement with UCVA in the MALK group compared to the FSALK group. The UCVA in the MALK group showed an improvement from 1 month postoperatively and it was significant at 2 and 3 years postoperatively ( $P=0.03,0.02$ respectively). In the series of 10 eyes with microkeratomeassociated ALK reported by Hashemi and Dadgostar, the UCVA improved from a logMAR of 1.20 preoperatively to 0.88 at the last mean follow-up of 10 months (comparable to Snellen VA of 20/300 preoperatively to 20/160 postoperatively). ${ }^{20}$ Our MALK cohort showed comparable UCVA improvement from 20/200 preoperatively to $20 / 100$ at 12 months and 20/63 at 36 months of follow-up.

There was a significant flattening of the corneal surface in the FSALK group postoperatively and this could be related to the fact that 5/7 eyes in this group underwent further PTK procedure along with the ALK to overcome the high $\mathrm{K}$ reading and also to remove any residual stromal opacities.

One eye in the MALK developed epithelial ingrowth that needed the graft to be replaced eventually. Previous reports have suggested that patients undergoing primary LASIK with a microkeratome, rather than a femtosecond laser, are at higher risk for developing epithelial ingrowth ${ }^{21}$, and we postulated that the same could happen in the case of ALK, as the corneal wound morphology in microkeratome keratoplasty, allowing inoculation of epithelium in the stromal interface, apply in both LASIK and ALK. The one graft failure in the FSALK group was due to bacterial keratitis in an already compromised ocular surface due to 2 previous PK surgeries.

In comparison to PK, both MALK and FSALK are non-penetrating procedures that are relatively safe, as most of the complications that could be encountered postoperatively, are dealt with medical approaches as in the case of donor rejection that was controlled with only topical steroid drops. Even when we had to replace the graft, like in the case of epithelial ingrowth or recurrence of the corneal dystrophy, we could achieve that with another lamellar graft, hence avoiding all complications associated with full thickness graft (eg; endothelial rejection, expulsive suprachoroidal hemorrhage). ${ }^{12}$ It is difficult to compare the visual outcome of our ALK to PK as almost half of the eyes that underwent ALK (6/14 eyes) already had a previous PK. However, Major astigmatism ( $\geq 5 \mathrm{D}$ ) that has significant effect over visual outcome, could be induced in $18 \%$ of eyes with PK. ${ }^{12}$ In comparison, both of our groups, when there was no associated PTK procedure, no change in the $\mathrm{K}$ reading was encountered postoperatively.

Limitation of the retrospective design of the study is that it did not yield information about exactly when the dystrophy recurred (either symptomatically or morphologically), as examination at the study visit only revealed morphological 
signs of recurrence at the point in time. It would be appropriate to identify onset of clinical recurrence when the patients report the symptoms, and with assessing the morphological recurrence at a regular interval in a longitudinal study design. In addition, the small number of eyes in this study makes it difficult to draw any definitive conclusions from our final results. Furthermore, the follow-up time in the 2 groups differed by approximately 97 months, in large part as a function of when FSALK was introduced at the authors' institution. However, this concern was addressed with cumulative incidence function analysis and by adding both groups in the analysis of the corneal dystrophy recurrence.

Both eyes of the bilateral cases were included in the study to increase the sample size. This could contribute to a bias because of a correlation effect in statistical analyses.

Our study showed a reduction in the $\mathrm{K}$ reading in FSALK with PTK group and a stable $\mathrm{K}$ reading in the MALK and the FSALK without PTK groups postoperatively, however; the surgically induced astigmatic correction was not calculated in our study and it would be beneficial in include it in future studies, especially in eyes with high preoperative astigmatism.

The anterior segment OCT was used to assess the depth of the lesion and hence the depth of lamellar dissection, however; in the case of FSALK, there was residual stromal opacity in some cases that needed further photoablation. In future studies, the extent of lamellar dissection below the predetermined OCT depth of corneal opacity should be documented and to be set at an extra depth to remove all anterior stromal opacity.

This case series represent a heterogeneous group of eyes with varying corneal dystrophies, surgical histories, and surgical techniques, which makes meaningful analysis of outcomes difficult. These drawbacks could be avoided in future studies with naïve eyes to better assess the visual results of anterior lamellar keratoplasty.

Despite these limitations, our series suggest that both FSALK and MALK procedures improve visual outcome, with negligible operative risk and postoperative graft rejection. There is still no consensus regarding the recurrence rate of anterior corneal dystrophies.

We described in our series the surgical treatment of anterior corneal dystrophy using FSALK, which provides many advantages over the conventional PK and MALK $^{22,23}$, and, in theory, the smooth interface made by the FALK should provide better visual quality. However, a prospective study design with larger patient samples is required before establishing a definitive role for FSALK in the treatment of anterior corneal stromal dystrophy.

\section{References}

1. Bron AJ. Genetics of corneal dystrophies. Cornea 2000;19:699-711.

2. Klintworth GK. Advances in the molecular genetics of corneal dystrophies. Am J Ophthalmol 1999;128:747-754.

3. Waring III GO, Rodrigues MM, Laibson PR. Corneal Dystrophies. 1. Dystrophies of the epithelium, Bowman's layer and stroma. Surv Ophthalmol 1978;23:71-122. 
4. Pandrowala H, Bansal A, Vemuganti GK, et al. Frequency, distribution, and outcome of keratoplasty of corneal dystrophies at a tertiary eye care center in south India. Cornea 2004;23:541-456.

5. Kawashima M, Kawakita T, Den S, et al. Comparison of deep lamellar keratoplasty and penetrating keratoplasty for lattice and macular corneal dystrophies. Am J Ophthalmol 2006; 142:304-309.

6. Vajpayee RB, Sharma N, Jhanji V, et al. One donor cornea for 3 recipients: a new concept for corneal tranplantation surgery. Arch Ophthalmol 2007;125:552-554.

7. Vajpayee RB, Vasudendra N, Titiyal JS, et al. Automated lamellar therapeutic keratoplasty (ALTK) in the treatment of anterior to mid-stromal corneal pathologies. Act Ophthalmol Scand 2006;84:771-773.

8. Hoffart L, Proust H, Matonti F, et al. Keratoplastis lamellaire anterieure assistee par laser femtoseconde. J Fr Ophthalmol 2007;30:689-694

9. Kezirian GM, Stonecipher KG. Comparison of the intralase femtosecond laser and mechanical keratomes for laser in situ keratomileusis. J Cataract Refract Surg 2004;30:804-811.

10. Schulze-Bonel K, Feltgen N, Burau H, et al. Visual acuities "hand Motion" and "counting Fingers" can be quantified with the freiburg visual acuity test. Invest Ophthalmol Vis SCI 2006;47:1236-1240.

11. Caldwell DR. Postoperative recurrence of Reis Bucklers' corneal Dystrophy. Am J Ophthalmol 1978;85:567-568.

12. Williams KA, Muehlberg SM, Wing SJ, et al, on behalf of all contributors. The Australian corneal graft registry, 1990-1992 report. Aust NZ J Ophthalmol 1993;21:1-48.

13. Dausch D, Landesz M, Klein R, et al. Phototherapeutic keratectomy in recurrent corneal epithelial erosion. Refract Corneal Surg 1993;9:419-424.

14. Medeiros FW, Stapleton WM, Hammel J, et al. Wafefront analysis comparison of LASIK outcomes with the femtosecond laser and mechanical microkeratomes. J Refract Surg 2007;23:880-887.

15. Mian SI, Soong HK, Patel SV, et al. In vivo femtosecond laser-assisted corneal surgery. Curr Opin Ophthalmol 2007;18:295-299.

16. Dinh R, Rapuano CJ, Cohen EJ, et al. Recurrence of corneal dystrophy after excimer laser phototherapeutic keratectomy. Ophthalmology 1999;106:1490-1497.

17. Lyons CJ, McCartney AD, Kirkness CM, et al. Granular corneal dystrophy. Visual results and pattern of recurrence after lamellar or penetrating keratoplasty. Ophthalmology 1994;101:1812-1817.

18. Abou Shousha M, Yoo SH, Kymionis GD, et al. Long-term results of femtosecond Laser-Assisted sutureless anterior lamellar keratoplasty. Ophthalmology 2011;118:315-323.

19. Springs $C L$, Joseph MA, Odom JV, et al. Predictability of donor lamellar graft diameter and thickness in an artificial anterior chamber system. Cornea 2002;21:696-699.

20. Hashemi H, Dadgostar A. Automated lamellar therapeutic keratoplasty with fibrin adhesive in the treatment of anterior corneal opacities. Cornea 2011;30:655-659.

21. Henry CR, Canto AP, Galor A, et al. Epithelial ingrowth after LASIK: clinical characteristics, risk factors, and visual outcomes in patients requiring flap lift. J Refract Surg 2012;28:488-492.

22. Hoffart L, Proust H, Matonti F, et al. Keratoplastis lamellaire anterieure assistee par laser femtoseconde. J Fr Ophthalmol 2007;30:689-694

23. Kezirian GM, Stonecipher KG. Comparison of the intralase femtosecond laser and mechanical keratomes for laser in situ keratomileusis. J Cataract Refract Surg 2004;30:804-811. 